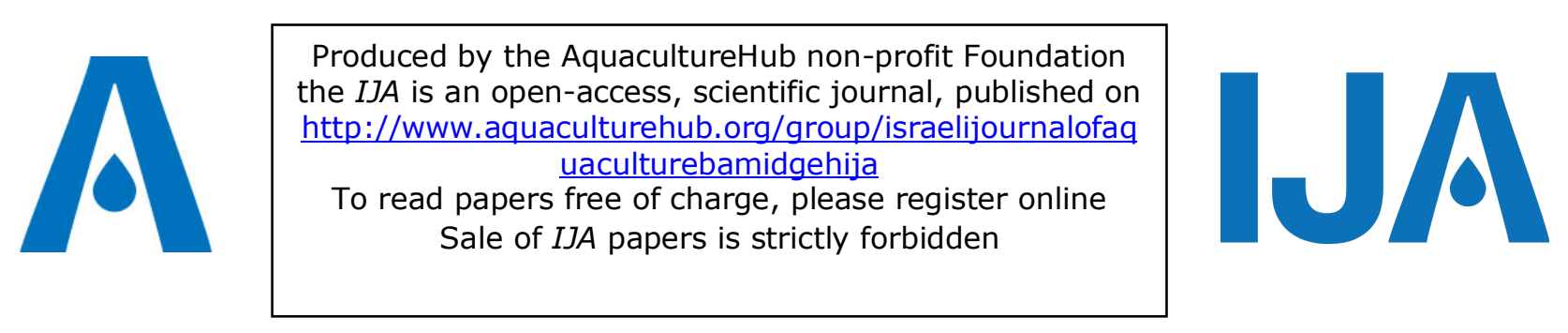

\title{
Adoption of Small Scale Coastal Cage Fish Farming in the Southwest Coast of India: Opportunities and Challenges
}

\author{
Aswathy Natarajan* and Imelda Joseph \\ Indian Council of Agricultural Research(ICAR), Central Marine Fisheries Research \\ Institute(CMFRI), Kochi 682018, India
}

Key words: cage fish farming, constraints, economic indicators, opportunities

\begin{abstract}
Cage fish farming is an emerging aquaculture technology in India. It is a low impact farming practice with high economic returns. ICAR-CMFRI in India had developed cost effective technologies for cage farming and popularised the technology through front line demonstrations in the marine and coastal waters in the country. We analysed the opportunities and constraints of coastal cage fish farming in Kerala state, in the south west coast of India. Economic indicators of selected farms revealed that cage farming is an economic viable technology in the coastal waters earning an average net profit of USD3,914 and internal rate of return (IRR) of $68 \%$. Coastal water pollution, inadequate financial capital, climate change impacts, high feed cost and lack of insurance facilities were reported as the major constraints in cage fish farming. The study indicated that cage fish farming has great potential for augmenting fish production and coastal livelihoods and emphasized the need for stringent regulations for mitigating coastal water pollution, institutional linkages for financial inclusion and insurance facilities for upscaling the technology.
\end{abstract}




\section{Introduction}

Cage fish farming technology was introduced in India by the Central Marine Fisheries Research Institute (ICAR-CMFRI), through development of hatchery technologies for high value finfishes, low cost cages and front line demonstrations in different maritime states. The successful front line demonstrations of open sea cage farming by the institute followed by development of low cost cages suited for the brackishwater areas led to its wide spread popularity among the coastal population. Kerala state located in the south west coast of India constitutes approximately $10 \%$ of India's total coastline. The state contributed an average marine fish production of 0.64 million $t$ in 2018 which was $18 \%$ of the total marine fish production in the country (FRAD, CMFRI, 2019). However the marine capture fishery in the state is at a stagnant stage and mariculture or aquaculture activities are considered as viable options for augmenting fish production in the state.

Although cage fish farming was initiated in the brackishwater areas of Kerala state through the interventions of some of the Non-Governmental Organisations(NGOs) from the beginning of the 21st century itself, it couldn't make any noticeable progress among the fish farmers in the state. The technology adoption process gained momentum after the development and popularisation of cost effective cage farming technology by the CMFRI. Eventhough the state has made considerable headway in coastal cage farming, upscaling of technology towards substantial contribution to fish production in the state is constrained by several factors. Identifying the opportunities and challenges from the farmers perspective will give impetus to the technology diffusion through developing appropriate strategies for addressing the challenges and harnessing the opportunities. In this context an attempt has been made to analyse the constraints and opportunities based on the information gathered from the adopted farmers.

Since the economic indicators play a key role in investment decisions in any farming technology, the study focussed on assessing the prospects of the technology based on economic indicators and potential area suitable for cage farming. The economic viability of cage fish farming was analysed by Aswathy and Joseph (2019), Shinoj et al., (2017); Azazy et al.,(2012) Conte et al., (2008); Das et al., (2009). The constraints in cage fish farming was analysed using Garrett's ranking technique.

\section{Materials and Methods}

The study was based on cross sectional analysis of 90 sample farmers who had adopted the cage fish farming technology in the brackish water areas in Kerala state. The respondents comprised of individual owners, partnerships and self -help group members. Square shaped Galvanised iron(GI) fish cages of dimensions $48 \mathrm{~m} 3(4 \times 4 \times 3 \mathrm{~m} 3)$ has been recommended by ICAR-CMFRI as the standard cages suited for the brackishwater areas in Kerala state. The economic viability of the adopted fish farms was analysed for assessing the potential for upsaling the technology for enhancing fish production, employment and income generation by utilising the potential area suitable for culture.

The economic and financial performance of cage farming was analysed using various indicators:

- Net profit

- $\quad$ Net Benefit-Earnings ratio

- Net Present Value (NPV)

- Internal Rate of Return (IRR)

- Benefit-Cost Ratio (BCR).

- $\quad$ Net profit $=$ Gross revenue minus all costs including operational cost, depreciation and interest on fixed capital

- Net Cash Flow (NCF)/Total Earnings (TE) ratio expresses the NCF or net benefit as a percentage of TE. A ratio of more than $10 \%$ can be considered as good (Tietze et al., 2001).

- The financial feasibility indicators such as NPV, BCR and IRR were calcuated at an expected life of 5 years for the fish cages and $15 \%$ discount rate.

- $\quad$ BCR is the ratio of present discounted benefits to the discounted cost.

- $\left.\quad B C R=\left\{\sum \mathrm{iBi} /(1+r) \mathrm{i}\right\} /\left\{\sum \mathrm{iCi} / 1+\mathrm{r}\right) \mathrm{i}\right\}$ 
- Where $\mathrm{Bi}$ is the total revenue earned at year $\mathrm{i}, \mathrm{Ci}$ is the total costs at year $i, i$ is the expected duration of culture in years and $r$ is the discount rate.

- IRR of an investment is the discount rate at which the net present value of costs (negative cash flows) of the investment equals the net present value of the benefits (positive cash flows) of the investment.

- $\left.\quad \mathrm{NPV}=\Sigma \mathrm{iBi} /(1+r) \mathrm{i}-\sum \mathrm{iCi} / 1+r\right) \mathrm{i}=0$

- Where NPV is the net present value and $r$ is the internal rate of return. BCR and IRR were calculated at a discount rate of $15 \%$.

The constraints in cage fish farming were analyzed using Garrett's ranking technique (Pandey and Dewan, 2006; Jimjel et al., 2015; Rahaman et al., 2015; Chidambaram et al., 2016; Virendra Kumar et al., 2017; Johnson et al., 2017). In this method, respondents were asked to rank the specific problems encountered in cage farming. The assigned rank was converted into a percentage position, which was subsequently transferred into the Garrett score. For each constraint, scores of individual respondents were added together and then divided by the total number of respondents. Thus, the mean score for each constraint has been ranked by arranging them in descending order.

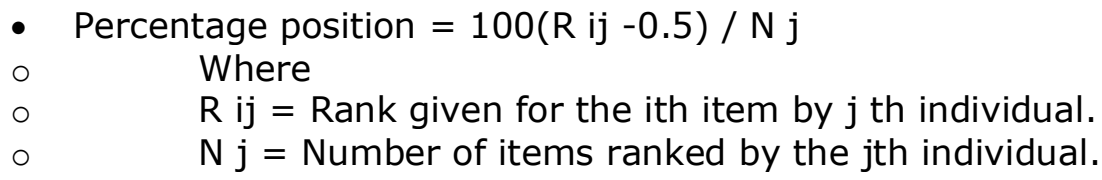

\section{Results}

The study was undertaken in the coastal water areas in Kerala to assess the prospects and constraints of cage farming technology. All the respondent farmers received partial financial assistance through the subsidy assistance scheme of the National Fisheries Development Board (NFDB) in India implemented through the ICAR-CMFRI project. The composite culture of seabass (Lates calcarifer) along with Pearl spot (Etroplus suratensis) was practiced by the adopted farmers.

\section{Socio-economic indicators of respondent farmers}

Among the respondent farmers, $44 \%$ earned a secondary school certificate, $11 \%$ had post-secondary education level, and $34 \%$ had college-level education, which indicated the preference of the cage farming technology adoption among the educated population. The majority of the farmers ( $47 \%$ ) had $1-2$ years' experience, while $13 \%$ of the farmers had no previous experience in cage farming. All the respondent farmers received technical assistance from ICAR-CMFRI. Concerning ownership of cage farms, $87 \%$ of the beneficiary farms were under single ownership, $9 \%$ under partnership and $4 \%$ under self-help groups(SHG) (Table 1). 
Table 1 Socio-economic characteristics of the respondent farmers

\begin{tabular}{|c|c|c|c|c|c|c|}
\hline \multirow{2}{*}{$\frac{\text { Particulars }}{\text { Education }}$} & \multicolumn{6}{|c|}{ Category } \\
\hline & & & & & & \\
\hline Category & $\mathrm{P}$ & UP & HS & HSS & College & Total \\
\hline No & 4 & 5 & 40 & 10 & 31 & 90 \\
\hline$\%$ & 4.44 & 5.56 & 44.44 & 11.11 & 34.44 & 100 \\
\hline \multicolumn{7}{|l|}{ Age } \\
\hline Category & $<30$ & $31-40$ & $41-60$ & $>61$ & Total & \\
\hline No & 27 & 36 & 24 & 3 & 90 & \\
\hline$\%$ & 30 & 40.00 & 26.67 & 3.33 & 100.00 & \\
\hline \multicolumn{7}{|l|}{ Experience } \\
\hline Category & No experience & $1-2$ years & $3-5$ years & $6-9$ years & $>10$ years & Total \\
\hline No & 12 & 42 & 23 & 10 & 3 & 90 \\
\hline$\%$ & 13.33 & 46.67 & 25.56 & 11.11 & 3.33 & 100 \\
\hline \multicolumn{7}{|l|}{$\begin{array}{l}\text { Ownership } \\
\text { of farms }\end{array}$} \\
\hline Category & Single & Partnership & SHG & Total & & \\
\hline No & 78 & 8 & 4 & 90 & & \\
\hline$\%$ & 86.67 & 8.89 & 4.44 & 100 & & \\
\hline
\end{tabular}

${ }^{1} \mathrm{P}:$ Primary, UP:Upper primary, HS:High School, HSS:Higher secondary

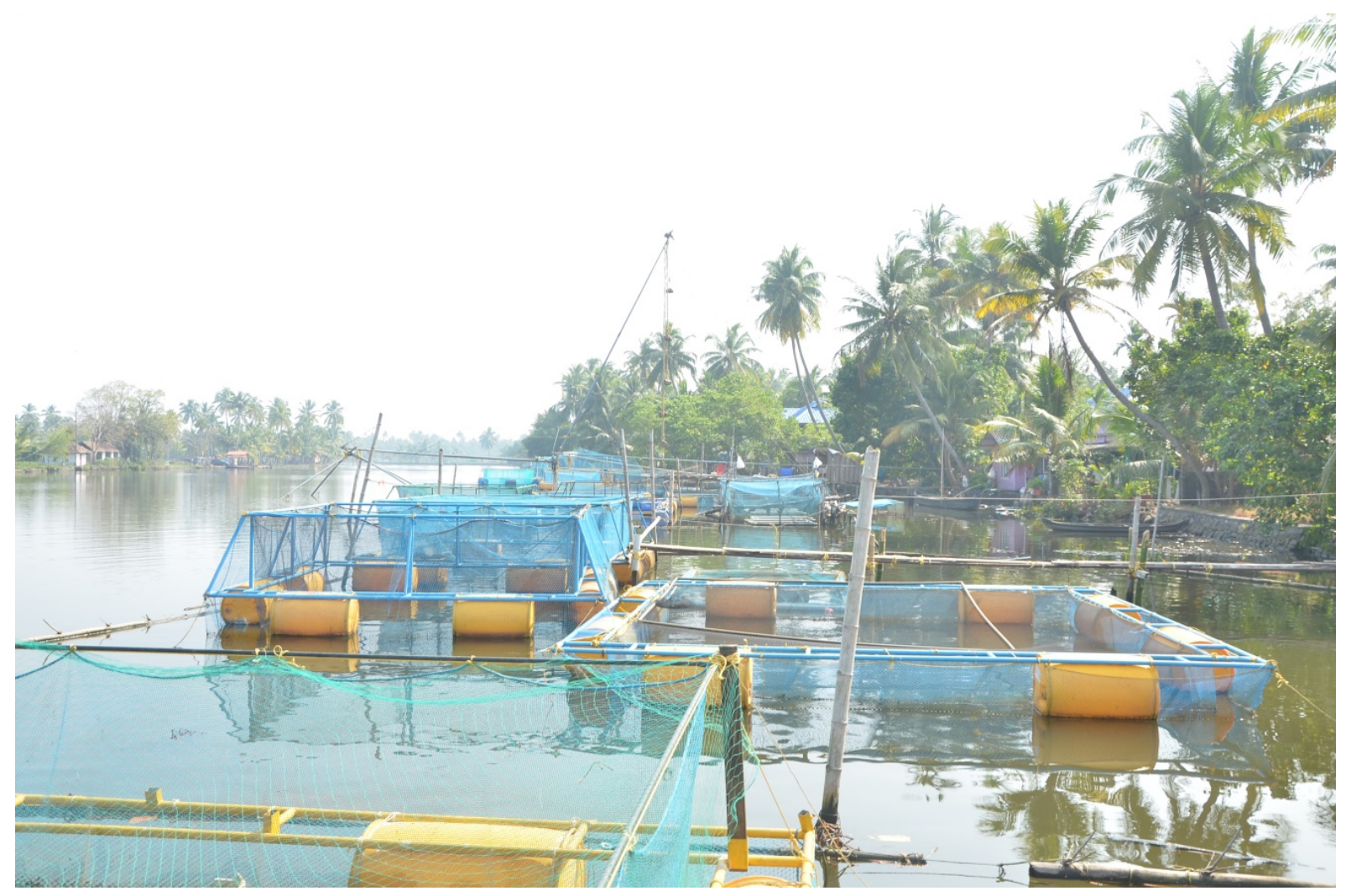

Figure 1 Coastal cage fish farming in Kerala 
Table 2 Economic viability of selected farm units

\begin{tabular}{lll}
\hline Economic indicators & \multicolumn{2}{c}{ Amount } \\
\cline { 2 - 3 } & USD & $\%$ \\
\hline Capital investment & & \\
Cost of cage and & 1248 & \\
Annual Depreciation & 250 & \\
Interest on investment & 150 & \\
Annual fixed cost & 400 & $(9.11)$ \\
Seed cost & 726 & $(16.53)$ \\
Feed cost & 2528 & $(57.56)$ \\
Other costs & 138 & $(3.14)$ \\
Labour cost & 600 & $(13.66)$ \\
Total operating cost & 3993 & $(90.92$ \\
Total cost & 4392 & $(100.00)$ \\
Revenue & 8306 & \\
Net profit & 3914 & \\
Net benefit-earnings ratio & 0.47 & \\
NPV & 6536 & \\
BCR & 1.38 & \\
IRR & $68 \%$ & \\
\end{tabular}

${ }^{1}$ The exchange rate used is 1 USD $=$ INR 70

${ }^{2}$ Figues in Parenthesis indicate percentages to total cost

Prospects of cage farming in the coastal waters in Kerala

Based on the economic indicators, small scale cage fish farming can be suggested as a profitable enterprise for upscaling in the coastal waters of Kerala for augmenting fish production and livelihoods. The state of Kerala has an estimated area of 46,128 ha of backwaters (Department of fisheries, GOK, 2019). If $10 \%$ of such potential areas are put into cage fish farming, the estimated production potential is 0.57 million tonnes of fish with an estimated production of 1 tonne of fish from a $48 \mathrm{~m}^{3}$ cage. The employment generation potential is 0.15 million person-days with at least one person getting employment in feeding and maintenance of 4 cage units.

\section{Constraint analysis}

Constraints in the adoption of cage farming were done using Garrett's ranking technique. The major constraints reported by the farmers in the order of ranking were water pollution with a score of 55.53 followed by inadequate financial capital (54.67), climate change impacts (50.60), high feed cost (50.56) and lack of insurance facilities (50.00). 
Table 3 Constraint analysis

\begin{tabular}{lll}
\hline Constraints & \multicolumn{2}{c}{ Garrett ranking } \\
\cline { 2 - 3 } & Score & Rank \\
\hline Coastal water pollution & 55.53 & I \\
$\begin{array}{l}\text { Inadequate financial } \\
\text { capital }\end{array}$ & 54.67 & II \\
Climate change impacts & 50.60 & III \\
High feed cost & 50.56 & IV \\
Lack of insurance & & V \\
facilities & 50.00 & \\
Net damage by mussels & 49.15 & VI \\
Poaching & 46.31 & VII \\
Marketing issues & 41.25 & VIII \\
Non-availability of quality & 38.50 & IX \\
seeds & 35.00 & X \\
Rats & 29.00 & XI \\
Cage design &
\end{tabular}

Pollution in the coastal water areas received the highest score among the constraints reported by the respondent farmers. Industrial effluents, along with waste disposal in the water bodies, caused the mortality of fishes in cages. The farmers insisted implementation of stringent regulations by the local authorities for preventing coastal water pollution.

Even though all the respondents received partial subsidy assistance provided by National Fisheries Development(NFDB) through ICAR-CMFRI- project, inadequate financial capital was reported as the second major constraint affecting the adoption of cage fish farming by the farmers. The farmers required adequate financial capital for meeting the day to day farming expenses, including feed cost since the returns from cage farming was realized nearly seven months after stocking. The growing interest in the adoption of cage fish farming as an alternate livelihood option by the small scale fish farmers underscores the need for institutional credit for better diffusion of the technology.

High cost for fish feed was ranked as the 4th important constraint affecting cage farming. The majority of the farmers depended on trash fish from the capture fisheries sector for feed, and a decline in the catches resulted in price escalations and an increase in production costs. Development of low-cost alternate feeds is essential for large scale expansion of coastal cage farming and reducing the pressure on capture fisheries stocks.

The respondent farmers reported difficulties with respect to marketing or low price realization for the cage farmed fishes. Cage farmed fishes realized a premium price due to their superior quality and freshness. However, few of the farmers faced difficulties in marketing and received a lower price than expected. Poaching was also reported as a constraint by the farmers, which could be minimized through manual monitoring of cages or installation of cameras in cage sites. The marketing challenges could be addressed by improving the entrepreneurial capabilities of fishers through capacity building or promoting farmer producer companies (FPOs) of cage fish farmers for exploring better market opportunities. FPOs are profit-oriented business organizations by the farmers promoted in the farming sector of the country, which has the greater capability of the transformation of rural communities (Trebbin and Hassler, 2012).

The farmers purchased seeds from the government hatcheries as well as few commercial hatcheries in the country. However, low growth and mortality of fishes due to poor quality of seeds were reported by the farmers who purchased seeds through agents. The constraints with regard to seed supply could be resolved through the promotion of local hatcheries of finfishes and nursery cages through the public-private partnership model for ensuring the quality of seeds. 
Rodents caused damage to nets and escape of fishes in cages. Rat traps put for the control of rodents will manage the rat menace to a certain extent. Few farmers in the respondent category reported that the present cage design had lower stability during excess water flow in the lakes and suggested for minor modification with an additional frame at the bottom for preventing the damage or loss of fishes during excess water flow in the lakes.

\section{Discussion}

The economic viability assessment of cagefish farming in the coastal waters revealed that cage fish farming has enormous potential for upscaling in the coastal waters of Kerala and enhancing the coastal livelihoods. Shinoj et al. (2017) and Aswathy and Joseph(2018) also pointed out the potential of cage fish farming for enhancing the farmers' income in India.

However, the constraints concerning cage fish farming reported by the farmers need to be seriously addressed for driving the technology towards more significant strides. De Silva and Phillips (2007), based on the review of cage farming in Asia, pointed out the increased dependency of cage-reared fish species upon fishery resources as feed inputs and trash fish as well as the availability of fingerlings as a significant challenge for cage fish farming in the in Asia. The study also suggested a better feed management strategy for increasing the efficacy of trash fish use, the use of pelleted feeds, and market incentives for farmers to adopt more environmentally sound feeding methods. A study by Taabeah et al. (2010) on the constraints in cage farming in Ghana also revealed that lack of funds to purchase input such as feed in the long run as the significant constraints affecting aquaculture and suggested for subsidizing feed cost for small-holders. Assessment of opportunities and challenges of cage fish farming in Zambia by Oilver et al. (2019) indicated that lack of quality fish seed and feed were the significant challenges faced by the aquaculture production companies in Siavonga district. From the results of the study, it could be concluded that the lack of financial capital for meeting the operational expenses as one of the significant challenges for aquaculture expansion by the small-holders in developing countries. Useful policy guidelines are, therefore, essential for the financial inclusion of small-holder aquafarmers through institutional linkages or subsidized inputs for aquaculture expansion in developing countries.

Climate change is a threat to fisheries and aquaculture in many countries across the world. Flooding in the brackish water areas due to erratic monsoon resulted in the mortality of fishes and economic loss to cage farms of a few of the respondents. The infestation of invasive mussels was also reported as a constraint which reduces the economic returns of cage farms. Although the infestation of invasive mussel species was reported to be the result of the discharge of ballast water, climate change is also suspected as a reason for the proliferation of invasive mussels in the coastal waters in the study area. The development of suitable adaptation strategies is essential for mitigating climate change impacts in cage fish farming.

Soto et al. (2008) suggested the adoption of the ecosystem-based approach for mitigating the climate change impacts in Aquaculture. Proper site selection and aquaculture zoning, as well as fastening the fish cages to the bottom or a holding structure and submersible cages, were also suggested as adaptation measures to withstand the climate change impacts.

The provision for insurance facilities for small scale aquaculture business occupies a significant role in the climate change scenario. There is no provision for insurance coverage of cage farms at present, and the farmers felt it was necessary to introduce insurance facilities to cover the risks due to climate change and other natural calamities. The catastrophic disasters due to climate change reported in the state in the recent past underscore the need for the introduction of insurance facilities for large scale expansion of cage fish farming in the state. Shinoj et al., 2017 reported that the risk associated with mariculture activities is high in India, and institutional mechanisms to address risk and uncertainties in the marine fisheries/ mariculture sectors are inadequate.

\section{Conclusion}

The study revealed that cage fish farming in the coastal waters of Kerala is an economically viable option and can be promoted for improving the coastal livelihoods and augmenting fish production in the state. The significant constraints reported by the farmers comprising coastal water pollution, inadequate financial capital, climate change impacts, lack of quality 
seeds, high feed cost, and difficulties in marketing need to be addressed on a priority basis for the widespread diffusion of the technology. Effective institutional linkages ensuring financial inclusion of the coastal population, stringent measures for mitigating coastal water pollution, the introduction of insurance facilities, and improving the entrepreneurial capabilities of farmers will undoubtedly give an impetus for the large scale commercialization of cage fish farming technology in the state.

\section{Acknowledgements}

The authors express their sincere gratitude for the Chairperson, NFDB for funding the ICARCMFRI project. Thanks are also due to the Director, CMFRI and Head, SEETTD, CMFRI for providing the necessary facilities for undertaking the research work.

\section{References}

Aswathy, $\mathbf{N}$ and Imelda, Joseph, 2019. Economic feasibility and resource use efficiency of coastal cage fish farming in Kerala. Econ. Affairs, 64 (1): 151-155.

Azazy, A., Hussien A. Hebicha \& Ahmed M. Nasr Allah, 2012. Estimated costs and returns for commercial cage production of fingerlings and table-size mullet (Mugil cephalus) in Dakhlia Governorate, Egypt. Egy. J. Aquaculture.

Chidambaram, P., T. Umamaheswari, S. Hameedullah Sheriefand M. Rajakumar, 2016. Techno-economic Analysis of Carp Farming Practices in Krishnagiri District, Tamil Nadu, India. Asian J. Agric. Ext. Econ. \& Socio. 12(1): 1-8 Article no.AJAEES.26953 ISSN: 2320-7027.

Conte, L., D.Y. Sonoda, R. Shirota \& J.E.P. Cyrino, 2008. Productivity and economics of Nile tilapia Oreochromis niloticus cage culture in South-east Brazil. J. Appl. Aquaculture, 20(1): 18-37.

Das, A.K., Vass, K.K., Shrivastava, N.P. \& Katiha, P.K., 2009. Cage culture in reservoirs in India (A Handbook). World Fish Center Technical Manual No. 1948. The World Fish Center, Penang, Malaysia.

De Silva, S.S. and Phillips, M.J.,2007. A review of cage aquaculture: Asia (excluding China). In: M. Halwart, D. Soto and J.R. Arthur (eds.), Cage aquaculture - Regional reviews and global overview, FAO Fisheries Technical Paper. No. 498, 241 pp.

FRAD, CMFRI, 2019. Marine Fish Landings in India 2018, Technical Report, CMFRI, Kochi Govt of Kerala, 2019. Fisheries hand book 2019, Department of fisheries, Government of Kerala, Vikas Bhavan, Thiruvananthapuram, 110pp.

Johnson, B., R. Narayanakumar, A. K. Abdul Nazar, P. Kaladharan and G. Gopakumar, 2017. Economic analysis of farming and wild collection of seaweeds in Ramanathapuram District, Tamil Nadu, Indian J. Fish., 64(4): 94-99, DOI: 10.21077/ijf.2017.64.4.61828-13

Katiha, Pradeep K. , Jena, J. K. , Pillai, N. G. K. , Chakraborty, Chinmoy and Dey, M. M.,2005. Inland aquaculture in India: past trend, present status and future prospects, Aquaculture Econ. Manage., 9(1): 237 - 264.

Oliver J. Hasimuna, Sahya Maulu, Concillia Monde and Malawo Mweemba, 2019. Cage aquaculture production in Zambia: Assessment of opportunities and challenges on Lake Kariba, Siavonga district, Egypt. J. Aquat. Res., 45 : 281-285.

Pandey, S.K. and Ritu Dewan, 2006. Constraints in fish farming practices in Uttar Pradesh, India-an analysis. J. Indian Fish. Assoc., 33: 183-189.

Rahman, Sk. M. , A. Ghosh, S. Pal and S. Nandi, 2015. A Comparison of resource use efficiency and constraints of Wastewater and freshwater fish production system in West Bengal , Econ. Affairs, 60(2): 249-255.

Shinoj, P., C. Ramachandran, A. Gopalakrishnan, K. Mohammed Koya, R. Narayanakumar, K. P. Salini and P. V. Sunil, 2017. Marine Fisheries Insurance in India: Status and prospects. Mar. Fish. Infor. Serv., T \& E Ser., No. 233:3-6.

Shinoj, P., George, Grinson, Narayanakumar, R., Aswathy, N., Ramachandran, C., and Gopalakrishnan, A., 2017. Priorities and Strategies to Boost Incomes of Marine Fisher Folk in India. Agric. Econ. Res. Rev., 30: 205-216.

Soto, D., Aguilar-Manjarrez, J., Brugère, C., Angel, D., Bailey, C., Black, K., Edwards, P., Costa Pierce, B., Chopin, T., Deudero, S., Freeman, S., Hambrey, J., Hishamunda, N., Knowler, D., Silver, W., Marba, N., Mathe, S., Norambuena, R., Simard, F., Tett, P., Troell, M. \& Wainberg, A., 2008. Applying an ecosystem-based 
approach to aquaculture: principles, scales and some management measures. In: D. Soto, J. Aguilar-Manjarrez \& N. Hishamunda, (eds.), Building an ecosystem approach to aquaculture. FAO/ Universitat de les Illes Balears Expert Workshop, 7-11 May 2007, Spain, Mallorca. Rome. FAO. FAO Fisheries Proceedings. No. 14: 15-35.

Taabeah Anane G, Frimpong EA, Amisah S, Agbo N., 2010.Constraints and opportunities in cage aquaculture in Ghana. In: Liping L, Fitzsimmons K. (eds.), Better science, better fish, better life: Proceedings of the ninth international symposium on Tilapia in aquaculture, 182-190.

Trebbin and Hassler, 2012. Farmers' producer companies in India: A new concept for collective action?. Environ. Planning, 44(2):411-427.

Virendra Kumar Vishwakarma, J. K. Guapt and Shampi Jain, 2017. Constraints analysis of fish production and marketing of fish farmers in kabirdham districts of Chhattisgarh. Trends Biosci., 10(22): 4343-4346. 